\title{
EDITORIAL: \\ Global Problems, Local Solutions: What Works, What Does Not, What Can We Do?
}

\author{
Khadija Khaja \\ Joseph Varga \\ Special Issue Co-editors
}

The inspiration for this special issue came at a faculty retreat held on a glorious late summer day on a bucolic campus. In such a setting, what else would Social Work and Labor Studies faculty think about but intractable problems and impossible solutions! We had been thinking of ways that our two disciplines, social work and labor studies, converge, and the obvious answer was that both were oriented towards problem-solving, as were other disciplines in the social sciences. But what were the problems we were trying to solve? Where did they originate and where were the solutions come from?

Two things seemed obvious, intuitive, and in need of specific attention of the type provided by a journal issue. First, many of the problems faced by the populations both disciplines serve were, if not new, then at least historically located in the emergent global order. And second, most solutions were being worked out at the local level, through some combination or coalition of actors attempting to fashion problem-solving institutions and methods that empowered at-risk populations. Thus was born the Global Problems and Local Solutions issue of Advances in Social Work. What was out there that could be shared amongst practitioners to bring best practices to problems at different local levels? Our hope was to bring in different approaches that could be applied across regions and disciplines in order to see what works, who was doing what, and if there were truly regional applications to problem solving that, with some adjustments, could be generally applicable at the local level given the ongoing processes of global emergence. We recognized that such a single journal issue could never be comprehensive, and that our target of potential contributors would necessarily be limited by disciplinary and professional boundaries. Yet in looking at the state of the game in local problem solving and empowerment, our 15 essays provide a valuable window into both the successes and ongoing difficulties of providing paths of resistance, preparedness, and pro-active power to vulnerable, at-risk communities.

Of course, empowerment must be more than just a buzzword when it comes to fashioning local solutions, and our collection of articles highlights the difficulties of using top-down power to promote bottom-up action. As contributor Bret Weber reminds us, the NASW Code of Ethics charges us to "enhance human well-being... with particular attention to the needs and empowerment of people who are vulnerable." So what our articles, and our experience shows, is that there are many paths to empowerment, and those paths are often blocked in various ways. In casting our net wide, we drew in reports from a wide-ranging field of experience, and in this, we consider our efforts a success. Indeed, the problems for vulnerable populations are not confined to a single area, or a limited set of circumstances. Global processes, while bringing the world's people

Khadija Khaja, Ph.D., is an Associate Professor at the Indiana University School of Social Work, Indianapolis. Joseph Varga, Ph.D., is an Assistant Professor in the Indiana University Labor Studies Program on the Bloomington campus. 
together in many ways, cause a myriad of seemingly unending and intractable problems. Given those conditions, we were certainly pleased with the vast array of problems, solutions, methods, and approaches in the submitted articles.

However, that very wide net and vast array of responses presents another challenge: organizing some sort of cohesive, readable summary. In an effort to bring some order from a diverse group of articles, we indentify three main paths to local solutions on offer in the case studies: government policy, legislation and state institutions; nongovernmental organizations (NGOs); and grassroots and community-based organizations. Of course, as experience and our articles show, efforts to solve problems at the local level are rarely attempted or achieved in homologous paths involving just one right way. Solutions are crafted in a global system; they require cooperation across boundaries, across disciplines, and through different levels of authority, organization, institutions, and networks. When they work, it is through these interactions, just as when they fail, it is usually within these interactions that efforts break down.

Along those lines, our essays are organized into three sections, based on what level of problem solving they engage. The categories, of course, will not be perfect, and often overlap, but each essay provides insight into state-centered, NGO, or community-based solutions in some measure and in some combination.

In looking at state-centered action, policy, legislation and institutions all received attention. Bromfield and Capous-Desyllas' work on the problems of human trafficking offers valuable information on how legislation is crafted through the formation of somewhat unlikely and often uncomfortable alliances. Here we see how views of what constitutes human trafficking, and indeed, what counts as empowerment, are neither simple nor subject to general agreement. Thus while the major players agree on the nature and scope of the problem, they vigorously clash over what defines the at-risk community. The result is legislation that, while helpful, stops short of being a real local solution. Likewise, Marquita Walker's work on displaced workers highlights the problems of crafting a policy solution that satisfies the vulnerable population while actually addressing the problem. Few issues appear more intractable than the problem of displaced workers in the new, flexible global economy. Walker shows that there are no easy answers, and points to ways that more local control might improve retraining programs. On a more hopeful note, Jones, Rotabi, Levy, and Gray, in their study of teaching innovations, point to ways that state-sponsored institutions can draw on local knowledge and experience to craft education programs that work to truly empower populations at risk from natural disaster. Their work demonstrates the power and knowledge that state institutions with proper support can direct and bring to bear on the thorniest and most immediate of global problems, those caused by ecological catastrophe. On the problems in the developing and vital field of gendered immigration, Agbényiga and Huang suggest ways that both state-centered institutions of higher learning in social work and NGOs can learn from a close study of women's immigration experiences. They point to the need for social work curricula to include a sub-category on gendered immigration in order to understand the diverse issues facing immigrant women at the local level. 
States will almost always have a role to play in crafting solutions, but often that role will be in concert with NGOs, which often take on the most active roles when local problems arise. As well, NGOs often are the go-between when coordination is necessary between state resources and community-based organizations. Agbényiga, Barrie, Djelaj, and Nawyn's article shows how refugee agencies play a key role in the re-settlement of the recently displaced within state systems. This is best accomplished, they found, by forging deeper ties between refugees, agencies that serve them, and local ethnic organizations to fashion a truly local set of solutions to one of the most severe global issues. Simmelink and Shannon's work on community-based aid for refugee communities highlights some major advantages and constraints in local problem solving. Their work indicates that while ethnic based refugee organizations can be more helpful for certain issues, mainstream refugee aid groups often are better equipped to assess the mental health issues that affect this troubled population. Des Marais, Bhadra, and Dyer's work on how Japan responded to disaster is a vital intervention into the local/state/NGO debate. Their work demonstrates how local and regional relief work can be enhanced by limited, targeted actions deeply based in local preparedness, infrastructure, and culture. Their case study serves another function by making an unimaginable event such as the tsunami/nuclear disaster legible and knowable. Similarly, Saleh Ahmed brings the popular concept of microfinance into focus by examining the actual workings of NGOs. His article dispels the myth that microfinance is a cure-all, while pointing to the importance of NGO work and large-scale goals such as the UN Millennium Development Goals. On the topic of fair trade certification, Charity Fitzgerald's article discusses the difficulties in establishing true fair trade systems through NGOs that provide information to local retailers linked to community-based efforts at supporting local agriculture and industry. Her conclusions on this important topic deal frankly with the contradictions and problems of free trade and encourage social work researchers to take a lead role in providing information to producers, retailers, and certifiers.

Many hail the grassroots and community-based organization as just such a cure-all, but of course, practitioners and academics know better, and several of our articles pointed to the difficulties of problem solving at any level, including the grassroots. Bret Weber's exciting piece points to the urgency of ecological action, while also highlighting the perils of cooperative efforts as they make their way up the power ladder. What begins as a grassroots community-based effort at sustainable economics runs into the problem of the growth-based economy at the larger level. Similarly, David K. Androff's insightful work on the problems of utilizing Truth and Reconciliation Commissions within a North American setting also points to the problems a grassroots group encounters as it confronts power. Hamilton and Erickson's article on urban heat islands urges social work professionals to become fully engaged in the issue of global climate change by pointing out the deleterious effects of the crisis on urban populations. They call on social workers to strengthen community efforts to form a sustainable ecological system and push state agencies into stronger action. Constantino, Rotabi, and Rodman's work on gendered violence also revolves around the struggle between community and grassroots-based action and power structures, as local solutions encounter the entrenched power of gender violence. Luca Sugawara, Hermosa, Delale, Hoffman, and Lupšić's article looks at how 
very local solutions deriving from community-based support for family involvement in children's education in post-war conditions, while no cure-all either, help to enhance the development of democracy and renewal in truly empowering ways. And finally, Ankita Deka makes a potentially important intervention in critical social work practice by showing how a human rights-based approach to systemic poverty can aid practitioners in engaging with community groups working to address the root causes of endemic economic and social inequity.

What each study shows is that no solution, local, regional, state-centered, or grassroots, fits every aspect of our global problems, and not even the most empowering bottom up effort will satisfy everyone involved. The collection of articles for this special issue double as a field report on the both the state of at-risk populations under emerging global conditions and a best practices update on how local organizations and institutions are trying to meet the challenges. There is so much more out there, mainly because for each global connection, there emerges a local problem. Our task as educators, researchers and citizens is empowering populations to craft their own solutions, utilizing every tool available. If these collected articles contribute to that effort, and we believe they do, the effort is worthwhile.

\section{Author note:}

Address correspondence to Khadija Khaja, Ph.D., Indiana University School of Social Work, 902 W. New York St., Indianapolis, IN 46202. E-mail: kkhaja@iupui.edu 